Article

\title{
Efficiency of Cassava Production in China: Empirical Analysis of Field Surveys from Six Provinces
}

\author{
Hailing Fu ${ }^{1}$, Yi Qu ${ }^{2, *}$ and Yi Pan ${ }^{1}$ \\ 1 Institute of Tropical Agricultural and Forestry, Hainan University, Haikou 570228, China; \\ hilary118@163.com (H.F.); 992445@hainu.edu.cn (Y.P.) \\ 2 Newcastle Business School, Northumbria University, Newcastle upon Tyne NE1 8ST, UK \\ * Correspondence: yi.qu@northumbria.ac.uk
}

Received: 13 July 2018; Accepted: 10 August 2018; Published: 13 August 2018

\begin{abstract}
Cassava is becoming increasingly important as an industrial raw material in China. However, an insufficient supply of cassava raw materials and the expanding demand for cassava in downstream-processing industries restricts the development of the cassava industry in China. This paper studies how to increase the scale of cassava planting and promoting cassava production efficiency using output-oriented Data Envelopment Analysis (DEA) modeling. Overall Technical Efficiency (OTE), Pure Technical Efficiency (PTE), and Scale Efficiencies (SE) of the cassava-production system in the major cassava production areas of China are calculated using Variable Returns to Scale (VRS). Results reveal that, in addition to the Guangdong province, the OTE of Guangxi, Hainan, Fujian, Yunnan, and Jiangxi is inefficient, with an OTE of less than 1. The largest cassava-planting province, Guangxi, has the lowest $S E$ with 0.551 . The PTE of Guangxi is close to the minimum with 0.344. The OTE of Guangxi is also the lowest among the five provinces with 0.190 . This study also presents ways to improve production efficiency. Results reveal that Guangxi has a large ratio of transverse adjustment on average. In the Guangxi province, $1.70 \%$ of the service cost and $1.72 \%$ of the labor cost need to be eliminated to keep the current output scale. Meanwhile, service and labor costs need to be reduced by 3164.85 and 3209.92, respectively, to achieve the best production efficiency. Further industrialization and large-scale cassava cultivation, increased yield, and strengthened cooperation with the Association of South East Asian Nations (ASEAN) and Africa are suggested as policy options to improve the cassava system in China.
\end{abstract}

Keywords: cassava production; overall technical efficiency; pure technical efficiency; scale efficiencies; output-oriented DEA; China

\section{Introduction}

Cassava (Manihot esculenta Crantz) is a species of tropical plant found in Asia, Africa, and South America [1]. It is a multipurpose crop with applications including fodder, biofuels, textiles, paper, adhesives, sweeteners, glues, and plywood [2]. Economic development and the advancement of industrial technology have changed the development of cassava from a food crop to an industrial raw material and energy crop. Additionally, in Africa and South America, more than two-thirds of the total production of cassava is consumed daily [3]. Cock [3] also suggests that dried cassava is the cheapest energy source in large areas of the lowland tropics. From feedstock production (source) to fuel combustion, Hu et al. [4] assess the net energy, the external cost of carbon dioxide $\left(\mathrm{CO}_{2}\right)$ emissions, and the cost of using cassava-based ethanol as an alternative automotive fuel based on its holistic lifecycle. Their research shows that the net energy yield of cassava-based ethanol is found to be 0.37 MJ/MJ, i.e., about $49 \%$ that of conventional gasoline. They conclude that cassava-based ethanol has great potential in the future. However, its cultivation is increasing worldwide, mainly for human 
consumption: cassava production increased from 230 million tons in 2010 to 277 million tons in 2013 [5]. It can be seen that the demand of cassava is growing. Today, cassava is one of the most cultivated plants in the world after wheat, rice, and maize [6].

Due to the limited areas of tropical conditions in China (defined as: annual accumulative temperature $\geq 10{ }^{\circ} \mathrm{C}$, frost-free days $\geq 280$ days, and annual average rainfall $\geq 1000 \mathrm{~mm}$ ), cassava is mainly planted in the provinces of Guangxi, Guangdong, Hainan, Yunnan, Fujian, and the south of Jiangxi Province. The total output of cassava in these six provinces accounts for $97 \%$ of the total output in China. Among them, Guangxi Province has the largest acreage, accounting for $60 \%$ of the total cassava output in China [7]. In 2011, the total output of tapioca starch reached a record high of 90.05 million tons. Compared with other ethanol-fuel raw materials, Jin and Sun [8] conclude that cassava is the most suitable starch material for ethanol-fuel production in China. In 2012, cassava ethanol-fuel production was 1.6 million tons, which is also the highest level recorded to date. The rapid development of the cassava-processing industry requires an adequate supply of raw materials (cassava raw material refers to cassava root, cassava starch, and cassava slices). However, there have been several changes in output levels.

Cassava output has gone from soaring to stagnating. Since 2009, China's cassava output has not exceeded $2 \%$ of global output and has had a decreasing trend, with total output hovering around 4.55 million tons (If not specifically mentioned in the paper, all the data are from FAOSTAT) for many years. The total output of cassava was 4.51 million tons in 2009 and 4.59 million tons in 2013. Meanwhile, the total output of cassava was far below that of other Southeast Asian countries. In 2013, cassava output in Thailand was 30.23 million tons, making a $41 \%$ increase compared with the output of 21.44 million tons in 2004. Vietnam's cassava output in 2013 was 9.74 million tons, forming a 167\% increase compared with the output of 4.59 million tons in 2004. However, statistics showed that, in the same year, China only made a $20 \%$ increment to 4.59 million tons compared with the output in 2004, which stood at 3.82 million tons. The increment of Chinese cassava output was much smaller than Thailand and Vietnam. Comparing China's output to Thailand's 25.64 million ton and Vietnam's 5.15 million ton outputs, it can be concluded that China has a long way to go to catch up with these countries in terms of cassava output.

The planting area of cassava also suffers from a slow increase. In 2009, the total planting area in China was 270,600 hectares and increased to 290,100 hectares in 2013. The average increase was only $2.2 \%$. Compared to the rest of the world, China ranks ninth in terms of planting area size with 290,100 hectares, while Nigeria is at the top with 3,850,000 hectares. These data show that the planting area not only has a slow increase, but is also considerably lower than countries that are highly developed in cassava production.

The yield of cassava is steadily diminishing. Due to technological advances, the yield witnessed a quick increase from 15.27 tons per hectare in 2002 to 16.27 tons per hectare in 2011, which marked the peak yield. The yield of cassava in China ranks sixth in the world, behind India, Indonesia, Thailand, Vietnam, and Ghana. The average yield of cassava in the world is 16.80 tons per hectare. Although the output per hectare in China is greater than the global-average level, it still has a gap to close when compared with the main cassava producing countries.

From a price point of view, the price of cassava raw material keeps rising due to increased demand. Theoretically, the joint interaction between China-produced and Association of South East Asian Nations (ASEAN)-produced cassava raw material should stabilize the price. In fact, ASEAN-produced cassava raw material accounts for nearly $80 \%$ market share in China. Therefore, farmers lost their pricing power in China [9]. There are several causes for cassava price changes. Firstly, the price of cassava raw material rises year by year because of the demand of downstream cassava-processing manufacturers. According to our investigation, due to the insufficient supply of cassava, some tapioca manufacturers are even processing cassava for less than four months per year. In Guangxi Province, the price of cassava root rose from 320 Yuan/ton in 2005 to 590 Yuan/ton in 2014 (one yuan was worth 0.16 US dollars in 2014). Simultaneously, the booming demand for cassava, especially in the 
domestic tapioca and alcohol industry, also pushes the price up. Secondly, the price of cassava is deeply influenced by output. After 2012, the general output and price showed the same downward momentum. In contrast, strong demand arises from the birth of several domestic ethanol producers, thus causing the price to rise. Thirdly, cassava price is also influenced by imported cassava raw material. The imported cassava keeps the price relatively stable in China. The establishment of the China-Asian Free Trade Zone (CAFTA) after 2010, which promotes trading cooperation between China and Southeast Asian countries, has also especially affected the price. Table 1 is the cassava supply and demand balance in China.

Table 1. Cassava supply and demand balance in China. ‘0000 Tons.

\begin{tabular}{|c|c|c|c|c|c|c|c|c|c|c|c|c|}
\hline Year & \multicolumn{2}{|c|}{2009} & \multicolumn{2}{|c|}{2010} & \multicolumn{2}{|c|}{2011} & \multicolumn{2}{|c|}{2012} & \multicolumn{2}{|c|}{2013} & \multicolumn{2}{|c|}{2014} \\
\hline Total raw material demand & 998.29 & & 733.03 & & 698.45 & & 923.93 & & 1016.99 & & 1087 & \\
\hline Total raw material supply in China & 332.10 & $33 \%$ & 107.80 & $15 \%$ & 138.00 & $20 \%$ & 141.10 & $15 \%$ & 183.40 & $18 \%$ & 186 & $17 \%$ \\
\hline Total imports & 693.90 & $70 \%$ & 649.66 & $89 \%$ & 589.38 & $84 \%$ & 817.38 & $88 \%$ & 880.92 & $87 \%$ & 899 & $83 \%$ \\
\hline
\end{tabular}

As one of the big cassava producers, China's cassava cultivation-process management is extensive but there is a gap between output per unit area and other advanced countries. At the same time, due to the rapid growth in demand for domestic cassava, the development of cassava planting lags behind in China. The imports of cassava in China have been increasing year by year, with an increasing dependence on foreign countries [11]. No significant increase has been found in planting area, yield, or production output from 2009 to 2014 in China. But, as one of the most important industrial raw materials, downstream-processing-industry demand has increased. Table 1 shows that China-produced cassava of $1,860,000$ tons only meets $17 \%$ raw-material demand and $83 \%$ of the cassava required must be imported from Thailand, Vietnam, and other ASEAN countries. The importing of cassava starch with high quality and low price, on the one hand, inhibits the price of domestic tapioca starch and, on the other hand, suppresses the motivation of farmers. The contradiction between the shortage of the supply of cassava raw materials and the increasing demand for cassava raw materials in the downstream-processing industry has become the bottleneck of the development of the cassava industry in China.

It can be seen from this analysis that China's cassava industry has entered a state of stagnation. One of the problems of the cassava industry in China is the contradiction between the insufficient supply of cassava raw materials and the expanding demand for cassava raw materials in the downstream-processing industry. The main purpose of this study is the evaluation of cassava-production efficiency of the six provinces, and to propose solutions for how to promote cassava-production efficiency. The rural survey has been conducted at the six major provinces (Guangxi, Guangdong, Hainan, Yunnan, Fujian, and Jiangxi) of cassava planting from the end of 2013 to the beginning of 2014, choosing sales income as the variable output and production material cost, machine cost, and labor cost as variable input. Based on output-oriented and constructing a Data Envelopment Analysis (DEA) [12] model of Variable Returns to Scale (VRS), Overall Technical Efficiency (OTE), Pure Technical Efficiency (PTE), and Scale Efficiency (SE) of cassava production in the main area of China will be measured. In simple terms, PTE indicates how far from optimal the process of converting inputs to outputs is, where optimal production is considered as producing maximum output using minimum input. $S E$ is a measurement of efficiency related to size, and overall technical efficiency is a product of $S E$ and PTE. These measurements will be used to identify ways to improve the efficiency of cassava production in these six provinces (Guangxi, Guangdong, Hainan, Yunnan, Fujian, and Jiangxi).

\section{Literature Review}

With the cassava industry's continued development in the world, more and more research results have appeared. 
In terms of cassava application, Jiang et al. [13] use a biochemical-process model to evaluate the bioenergy potential of cassava on marginal land. They suggest that cassava is one of the most promising plants for ethanol-fuel production in the tropics and subtropics. In China, plant-based bioenergy has to be developed on marginal land to avoid impacting food security. In the view of plant-based bioenergy, the research results show that the extraction of land resources should also consider the growth requirements of cassava, including temperature, precipitation, soil, topography, and so on. In order to assess the sustainable development of bioenergy from cassava, Jiang et al. [14] find that land resources that were suitable for the development of cassava bioenergy have continuously decreased in China since 1990. After considering changes to land use, climate, and water footprint, they point out that Guangxi is the most suitable place to develop cassava bioenergy, followed by Fujian, Guangdong, and Yunnan. On the view of world food security, Kolawole et al. [15] conclude that an increase in the production of cassava to sustain world food security needs improved machinery to allow its continuous cultivation and processing in Nigeria. On the one hand, mechanization can increase cassava output; on the other hand, they suggest producing a cassava variety with a regular shape for easy harvesting and mechanization. Poku, Birner, and Gupta [16] use a comparative case-study approach of a public and private cassava grower scheme in Ghana and focus on rapidly developing domestic value chains in Africa's emerging bioeconomy. They conclude that firms' capacity and commitment to design contracts with embedded support services for growers are essential to smallholder participation and the long-term viability of these arrangements. Public-private partnerships in grower schemes can present a viable option that harnesses the strengths of both sectors and overcomes their institutional weaknesses.

In terms of a research indicator, many factors can potentially affect profit efficiency in agriculture. Oladeebo and Oluwaranti [17] define profit inefficiency as profit loss as a result of not operating on the profit frontier given farm specific prices and resource base. Abdulai and Huffiman [18] propose factors that explain profit inefficiencies in the tropical agricultural sector, including nonfarm employment, education, credit availability, the average age of the head of the household, distance to market, and regional dummies. In order to gain a deeper understanding of the factors influencing the poverty of farmers in Nigeria, Amao and Awoyemi [19] use the Foster-Greer-Thorbecke [20] poverty measure and Totib regression model to analyze the cassava industry. The results show that the gender, age, extension, crop yield, marital status, labor force, input, and education status are the factors influencing the adoption of cassava-seed varieties, while family size and cassava yield are the main factors determining whether farmers adopt the improved varieties. Awoyinka [21] analyzes the importance of effective policy supporting the sustainable development of the cassava industry in Nigeria. The conclusions are, on one hand, that government should provide farmers with relevant information to promote the domestic cassava market circulation; and, on the other hand, that government needs to strengthen the technical training of farmers to improve farmers' planting level. Awoyinka [21] shows that cassava supply mainly depends on the price of the previous year, while price is related to the government's commitment to income security programs and plans. With the development of cassava ethanol fuel, the demand for cassava is also growing rapidly. As the research result of Yang and Huang [22] showed, one of the key factors affecting the cultivation of cassava is the cultivated land area and nonagricultural employment status. Another key factor affecting the yield of cassava is the application of fertilizer, varieties, and the adoption of high-yield technology. Due to the rapid development of the cassava ethanol-processing industry in China, Yang and Huang [22] suggest that raising the yield is one of the ways to solve the shortage of cassava raw material supply and the key factors affecting cassava yield are fertilizer application status, varieties, and high-yield technology. They also point out that the key factor affecting farmers' cassava planting is the cultivated land area of farmers.

In terms of research approach, different methodologies have been used on cassava production efficiency. However, few studies use an output-oriented DEA model of VRS approach to measure the production efficiency of cassava in the main producing areas from the perspective of output. This paper addresses this gap and provides a novel and useful analysis. Awerije and Rahman [23] use a DEA model 
to study profitability, technical, cost, and allocative efficiencies of cassava production. Results show that cassava production is profitable and the overall profit margin is 1.93. Mean levels of technical, cost, and allocative efficiencies are low, which are estimated at 40\%,29\%, and 73\%, respectively. Meanwhile, Awerije and Rahman [23] focus on the technical and SE of the cassava-production system in Delta State, Nigeria. Their study examines the level of technical and scale efficiencies of the cassava production system of 278 cassava farmers in Delta State by applying a two-stage DEA approach. Results reveal that PTE is significantly lower at the production stage, 0.41 , vs. 0.55 for the processing stage, but $S E$ is high at both of the stages, implying that productivity can be improved substantially by reallocation of resources and adjusting operation size. Ji, Fu, and Min [24] use Cobb-Douglas production function analysis input-output status of Guangxi, Guangdong, Hainan, Yunnan, Fujian, and Jiangxi provinces. Most of these studies focus on the influencing factors of production efficiency, such as education, gender, and land area. The approach of two-stage DEA and Cobb-Douglas production function are used in the research.

\section{Methodology}

The research of agricultural productivity and efficiency is useful in making decisions on how to increase productivity within a region. DEA or Stochastic Frontier Analysis (SFA) is one of the main analysis methods that can be used in frontier-technique analysis. Marinoni [25] suggests that the method of DEA or SFA helps to better target potential investments if policies and investments are targeted at increasing efficiency and productivity within a region.

\subsection{Production Frontiers}

Normally, production-technology relationships are often described with production-possible sets. The production-possible sets are the set of all feasible inputs and output vectors under the established production technology. It shows the relationship among the three elements of input, output, and technology in the process of production. The function is specified as follows:

$$
\mathrm{P}(x)=\{y:(x, y) \in T\} \text { and } \mathrm{L}(y)=\{x:(x, y) \in T\}
$$

where $x$ is input of production factors, $\mathrm{y}$ is output, $\mathrm{L}(\mathrm{y})$ is all the sets of possible inputs, $\mathrm{P}(x)$ is all the sets of possible output, and $T$ is the specific technical level.

Under the condition of determining production factors and the price of output, an effective production state is the maximization of output and minimization of input. The hypersurfaces in the space formed by all the active production sites $(x, y)$ are called the production frontiers in the sets of possible production.

\subsection{Technical Efficiency (TE)}

Farrell first proposed the use of production frontiers to measure production efficiency. The calculation of TE is based on the production frontiers. The formula is:

$$
\text { Technical efficiency }=\text { Actual output/Production frontiers. }
$$

There are two approaches to estimate the production frontier: one is parameter-type function and the other is nonparametric functions. The parameter approach needs to assume the function form of the production function, and the nonparametric method does not. Aiger and Chu [26] adopted the first suggestion of Farrell, and created SFA. On the basis of Farrell's research, Charnes, Cooper, and Rhodes [27] created the DEA approach, and first adopted this method to research production efficiency. 


\subsection{Output-Oriented of VRS-DEA Modeling}

DEA is a type of data-oriented performance-evaluation approach that measures each Decision Making Unit (DMU) with multiple inputs and multiple outputs. DEA can be categorized into two kinds of DEA models: Constant Returns to Scale (CRS), and Variable Returns to Scale (VRS). TE of CRS is the overall comparison between resource-allocation efficiency and resource-utilization efficiency of those DMUs. TE of VRS refers to the production efficiency influenced by the factors like management and technology. The research shows that the increment of Total Factor Productivity (TFP) comes from the improvement of both technology and efficiency. $S E$ unveils the gap between the real scale and the optimal scale of the production.

DEA model can be categorized into two types according to different perspectives of input and output for the research. One is input-oriented and the other is output-oriented. Of these two, the former gives the definition of scale-down production frontiers when output is invariable, while the latter gives the definition of scale-up production frontiers when the input is invariable. Actually, both of them present measurement analysis for the same questions, though in two different perspectives of input and output. Therefore, they share the same production frontiers and a very slight difference for the efficiency value after measurement [28]. Considering the one-year data collected for this research, the output-oriented VRS of the DEA model is adopted in the analysis because people dealing with cassava production always put the maximized output as the priority when input is at a fixed level.

In order to measure cassava output production efficiency clearly, the output-oriented DEA model was chosen. Let $\mathrm{N}$ represents the number of DMUs, each DMU has K input factors produce and $\mathrm{M}$ outputs, production-possible collection are $\mathrm{T}_{\mathrm{V}}$ and $\mathrm{T}_{\mathrm{n}}$, and calculating the $i$ DMU's relative efficiency value. Output-oriented of VRS of DEA modeling is as follows:

$$
\operatorname{Max}\left[\alpha_{v}+\varepsilon\left(e_{1}^{T} S A+e_{2}^{T} S B\right)\right]
$$

s.t.

$$
\left\{\begin{array}{l}
\sum_{i=1}^{n} \lambda_{i} X_{i}+S A=X_{0} \\
\sum_{i=1}^{n} \lambda_{i} X_{i}-S B=\alpha_{v} Y_{0} \quad \lambda_{i} \geq 0, i=1,2, \ldots, n . S A \geq 0, S B \geq 0 \\
\sum_{i=1}^{n} \lambda_{i}=1,
\end{array}\right.
$$

where $S A$ and $S B$ are the slack variables, $\varepsilon$ is the perturbation, $\lambda$ is the unit vector of $N \times 1$, and $\beta$ is the relative efficiency of DMUs. $\beta \in[0,1]$. When $\beta$ equals $1, \mathrm{DMU}$ is efficient and DMU is on the production frontiers. At the same time, the DMU cannot create more output when the input is determined. Input quantity cannot be reduced if output is determined. When $\beta<1$, the DMU is inefficient.

Meanwhile, its change also reflects the influence placed on TFP by increasing input. OTE represents the technology efficiency when the returns to scale stay unchanged. In contrast, PTE refers to the Technical Efficiency when the returns to scale fluctuate. The relationship between OTE, PTE, and SE is $O T E=P T E \times S E$. When $O T E=1$, it shows that, if the output and input of DMUs are efficient, PTE and $S E$ are efficient as well. When $P T E=1$, it shows that at the current technological level, the use of its input resources is efficient. The fundamental reason for its failure to achieve comprehensive and effective results is that its scale is invalid. Therefore, focus is needed on how to make better use of its scale efficiency.

\subsection{Data and Research Area}

For the whole project, first-hand information was collected on the production of the major cassava-producing areas in Guangxi, Guangdong, Hainan, Yunnan, Fujian, Jiangxi (the output of 
cassava in these six provinces accounts for $97 \%$ of China). Distribution of respondents in each province is shown in Table 2.

Table 2. Distribution of respondents in each province.

\begin{tabular}{lcc}
\hline Province (County) & Household Total & \% \\
\hline Guangxi (Nanning, Hepu) & 39 & 12.15 \\
Guangdong (Zhanjiang, Maoming, Yunfu) & 73 & 22.74 \\
Yunnan (Baoshan, Wenshan, Honghe) & 62 & 19.31 \\
Hainan (Chengmai, Danzhou, Dunchang, Qiongzhong, Baisha) & 105 & 32.71 \\
Fujian (Datian) & 12 & 3.74 \\
Jiangxi (Dongxiang) & 30 & 9.35 \\
Total & 321 & 100 \\
\hline
\end{tabular}

The data were collected between December 2013 and February 2014 in the six provinces studied. During the research, 450 questionnaires were handed out and 321 of them were returned and made available for the research. The questionnaires mainly dealt with four aspects: the basic information of the families, the output of cassava and its production costs, the sales performance of cassava, and the production organizations. Excel was used to process the data of basic information of the respondent's family. The processed data are shown in Table 3. In addition to Guangdong, farmers whose cassava-planting income accounted for $18 \%$ of total household income were also selected as research samples (Guangdong is a developed province in China and farmers have many other sources of income. Therefore, the income from planting cassava is diluted by other incomes). Except Guangdong and Fujian, we chose cassava-planting land to account for more than $27 \%$ of household-owned land in other provinces. So, research samples are effective and reasonable.

Table 3. Basic information of respondent's family.

\begin{tabular}{|c|c|c|c|c|c|c|c|c|c|}
\hline Area & $\begin{array}{c}\text { Total } \\
\text { Family } \\
\text { Size (TFS) } \\
\text { (Person) }\end{array}$ & $\begin{array}{l}\text { Labor } \\
\text { Force } \\
\text { (LF) } \\
\text { (Person) }\end{array}$ & $\begin{array}{c}\text { LF/TFS } \\
(\%)\end{array}$ & $\begin{array}{l}\text { Quantity of } \\
\text { Land-Holding } \\
(\mathrm{QLH})\left(\mathrm{hm}^{2}\right)\end{array}$ & $\begin{array}{c}\text { Cassava } \\
\text { Planting } \\
\text { Area } \\
(\mathrm{CPA})\left(\mathrm{hm}^{2}\right)\end{array}$ & $\begin{array}{l}\text { CPA/QLH } \\
(\%)\end{array}$ & $\begin{array}{c}\text { Total } \\
\text { Household } \\
\text { Income } \\
\text { (THI)(Yuan) }\end{array}$ & $\begin{array}{c}\text { Cassava } \\
\text { Planting } \\
\text { Income } \\
\text { (CPI) } \\
\text { (Yuan) }\end{array}$ & CPI/THI (\%) \\
\hline Guangxi (GX) & 229 & 130 & 56.77 & 69.44 & 39.97 & 57.56 & $1,458,568$ & 692,987 & 47.51 \\
\hline Guangdong (GD) & 259 & 166 & 64.09 & 17.47 & 6.29 & 36.00 & $1,009,000$ & 43,618 & 4.32 \\
\hline Yunnan (YN) & 184 & 102 & 55.43 & 84.39 & 26.57 & 31.48 & $1,125,817$ & 553,770 & 49.19 \\
\hline Hainan $(\mathrm{HN})$ & 376 & 192 & 51.06 & 68.7 & 49.37 & 71.86 & $3,104,910$ & 548,750 & 17.67 \\
\hline Fujian (FJ) & 81 & 42 & 51.85 & 13.33 & 6.65 & 49.89 & 615,000 & 132,703 & 21.58 \\
\hline Jiangxi (JX) & 155 & 90 & 58.06 & 21.67 & 30.53 & 140.89 & N/A* & $\mathrm{N} / \mathrm{A}^{*}$ & - \\
\hline Total & 1284 & 722 & 56.23 & 275 & 159.38 & 57.96 & $7,313,295$ & $1,971,828$ & 26.96 \\
\hline Avg.household (GX) & 5.87 & 3.33 & 56.73 & 1.78 & 1.02 & 57.30 & $37,399.18$ & $17,768.9$ & 47.51 \\
\hline Avg.household (GD) & 4.89 & 3.13 & 64.01 & 0.33 & 0.12 & 36.36 & $19,037.18$ & 822.98 & 4.32 \\
\hline Avg.household (YN) & 5.26 & 2.91 & 55.32 & 2.41 & 0.76 & 31.54 & $32,166.2$ & $15,822.98$ & 49.19 \\
\hline Avg.household (HN) & 4.64 & 2.37 & 51.08 & 0.86 & 0.62 & 72.09 & $41,958.24$ & 7415.54 & 17.67 \\
\hline Avg.household (FJ) & 6.75 & 3.50 & 51.85 & 1.11 & 0.55 & 49.55 & 51,250 & $11,058.6$ & 21.58 \\
\hline Avg.household (JX) & 5.34 & 3.10 & 58.05 & 0.75 & 1.05 & 140.00 & - & - & - \\
\hline Avg. China & 5.06 & 2.84 & 56.13 & 1.1 & 0.64 & 58.18 & $3,7504.08$ & $10,111.94$ & 26.96 \\
\hline
\end{tabular}

N/A* Only two out of 30 returned questionnaires were completed including the total household income and cassava-planting income from Jiangxi Province, which cannot be used as effective statistical data in this research.

\subsection{Input-Output Analysis of Cassava Production in Six Provinces}

The input set and output set were built before VAR modeling was run. For research indicators, the net income originating from selling cassava is utilized in the output index, while the costs for materials and services on each hectare of land and costs for labor are utilized in the input index. In the meanwhile, indicators that can reflect technological progress were chosen, such as varieties and fertilizers. (The materials and services contain varieties, fertilizers, pesticides, fuel energy while labor was needed for sowing, real tillage, harvest, and straw burning). Fertilizers and pesticides were used here as part of the input indicators because they have a great impact on the output of cassava. The cost of labor is used here as another part of input indicators because the increased cost for human 
labor, caused by urbanization, also places a huge influence on the production efficiency. The cost of seeds is not considered to be part of the input indicators. This is because the influence seeds have on output efficiency is hard to assess as farmers usually utilize the seed stems left from the previous year for production. In summary, one output indicator and two input indicators are used in the research with six provinces functioning as DMUs to achieve the freedom of DMU choices and to comply with features of the same type.

Table 4 shows that Guangdong is the province with the best production efficiency of output and input. It outperforms other provinces with a total production cost of 7447.35 Yuan/ha, and output of 33.53 Tons/ha. Guangxi is the province with the highest cost and top-two output of cassava planting. Hainan is the province with the highest output, the highest sales income, and top-two production cost. Fujian is the province with the lowest production cost, the lowest sales income, and the lowest output. The data are helpful to measure cassava production efficiency in five provinces.

Table 4. Cassava production input-output analysis of six provinces in 2014.

\begin{tabular}{|c|c|c|c|c|c|c|}
\hline Province & Output (Ton/ha) & $\begin{array}{l}\text { Sales Income } \\
\text { (Yuan/ha) }\end{array}$ & $\begin{array}{l}\text { Total Production } \\
\text { Cost (Yuan/ha) }\end{array}$ & $\begin{array}{l}\text { Input Cost of Material } \\
\text { and Service (Yuan/ha) }\end{array}$ & $\begin{array}{l}\text { Machine Cost } \\
\text { (Yuan/ha) }\end{array}$ & $\begin{array}{l}\text { Labor Cost } \\
\text { (Yuan/ha) }\end{array}$ \\
\hline Guangxi & 31.94 & $17,886.40$ & $13,522.05$ & 5030.40 & 1350.00 & 7141.70 \\
\hline Guangdong & 33.53 & $20,118.00$ & 7447.35 & 1865.55 & 1650.00 & 3931.78 \\
\hline Yunnan & 27.08 & $15,977.20$ & $12,146.40$ & 2738.85 & 1350.00 & 8057.51 \\
\hline Hainan & 38.76 & $21,318.00$ & $13,398.30$ & 3016.50 & 1500.00 & 8881.74 \\
\hline Fujian & 25.14 & $13,827.00$ & 9623.55 & 2440.95 & 1500.00 & 5682.65 \\
\hline
\end{tabular}

\section{Results and Discussion}

\subsection{The Basic Results}

Looking at cassava-planting input-output analysis of Table 4 in Section 3.5 and output-oriented VAR of Section 3, DEAP2.1 [29] was used to measure the planting cost of cassava among the six provinces. In the procedure, those external factors, such as environment and CPI, are excluded from consideration of its influence on the research result. Summary statistics of the sample farms were presented in Table 3 in Section 3.4.

In Table 5, for the six provinces, only Guangdong DEA is efficient. OTE, PTE, and SE in Guangdong all stand at 1 , which is on the production frontiers. They represent optimal efficiency and thus become the benchmark for the other five provinces. The highest output of cassava in Guangdong is 1,267,065 Yuan; the lowest cost for materials and services is 186.566 Yuan; and the lowest cost for human labor is 393.178 Yuan. The data show the universality of Guangdong province's input efficiency and output efficiency in its cassava production and 12670.65 is the best output target.

Table 5. Six province cassava production efficiency (DEA) in 2014.

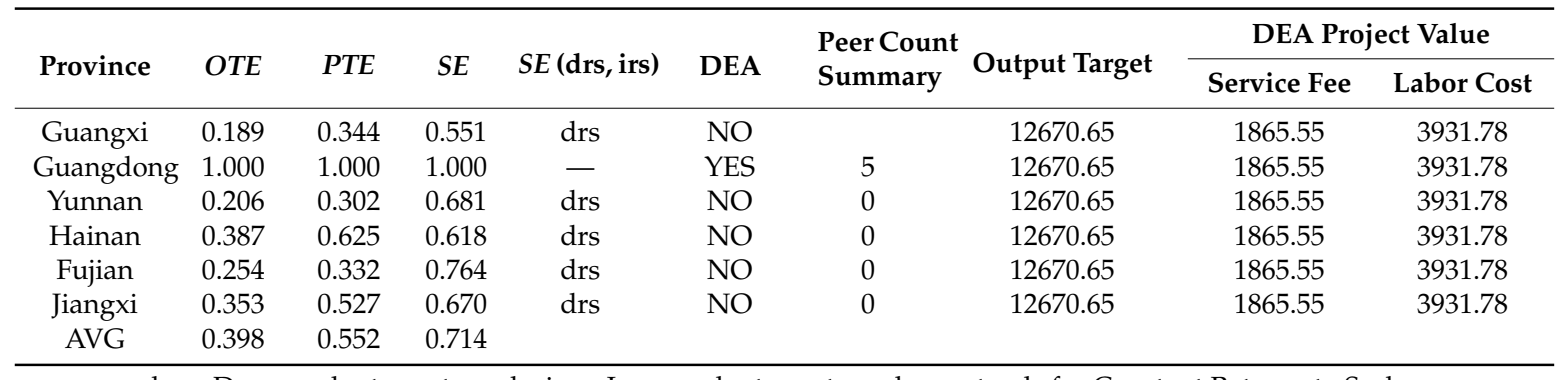

drs = Decreased returns to scale, irs = Increased returns to scale, - stands for Constant Returns to Scale.

The other five provinces have decreased returns to scale or states in which there exists no or very low technology efficiency, along with the start of relaxation in both input and output. A phenomenon of this kind reflects an irrational structure of input and output that exists in these five provinces. 
In terms of PTE of five provinces, Yunnan is the lowest with 0.302 , and PTE of Guangxi is 0.344 . PTE of Hainan is lower than Guangdong with 0.625 . In terms of $S E$ of the five provinces, the largest cassava-planting province, Guangxi, is the lowest $S E$ with 0.551 , and the $S E$ of Fujian is relatively optimal with 0.764 . Among them, Guangxi's OTE stands at the lowest level of 0.189 . The data show that enlarged production scale is needed to promote the $S E$ and OTE, with the current input staying unchanged. It shows that the cassava-production efficiency and planting management in Guangxi need to be improved. Compared with Guangxi, Fujian, Yunnan, Hainan's OTE is highest with 0.387, but it is still lower than 1; DEA is nonefficient.

In summary, in order to achieve the desired OTE in Guangxi, Yunnan, Hainan, Fujian, and Jiangxi, one of the strategies is expanding the production scale under the existing investment. The farther PTE is from the standard value 1 , the larger output scale needs to be adjusted.

\subsection{How to Improve TE}

When DMUs are nonefficient, the improvement measures can be found through the projection of each DMU on the production frontier $\left(X^{*}, Y^{*}\right)$.

$$
\begin{gathered}
X^{*}=\theta_{v}^{*} X_{0}-S A^{*}=\sum_{i=1}^{n} \lambda_{i}^{*} X_{i} \\
Y^{*}=Y_{0}+S B^{*}=\sum_{i=1}^{n} \lambda_{i} Y_{i}
\end{gathered}
$$

In order to make each DMU to be efficient, adjustments to output and input $\left(\Delta X_{0}, \Delta Y_{0}\right)$ :

$$
\begin{aligned}
\Delta X_{0} & =X_{0}-X^{*} \\
\Delta Y_{0} & =Y^{*}+Y_{0}
\end{aligned}
$$

After adjusting DMUs, the input and output $\left(X^{*}, Y^{*}\right)$ is pure technology effective. In fact, that is an effective way to improve the nonefficient DMUs, and provide policy suggestions for policy-makers.

Using DEAP 2.1, the output redundancy of each DMU was analyzed, and further proposed the efficiency improvement scheme in Table 6.

Table 6. Five province cassava-production efficiency DEA improvement in 2014.

\begin{tabular}{cccccccc}
\hline \multirow{2}{*}{ Province } & \multirow{2}{*}{ Radial Movement } & Radial Movement (\%) & \multicolumn{2}{c}{ Slack Movement } & \multicolumn{2}{c}{ Slack Movement (\%) } & \\
\cline { 4 - 6 } & & & Service Fee & Labor Cost & Service Fee & Labor Cost & \\
\hline Guangxi & 8306.30 & 0.66 & -3164.85 & -3209.92 & 1.70 & 1.72 & 0.344 \\
Yunnan & 8839.85 & 0.70 & -873.30 & -4125.73 & 0.47 & 2.21 & 0.302 \\
Hainan & 4750.95 & 0.37 & -1150.95 & -4949.96 & 0.62 & 2.65 & 0.625 \\
Fujian & 8467.20 & 0.67 & -575.40 & -1750.87 & 0.31 & 0.94 & 0.332 \\
Jiangxi & 5998.45 & 0.47 & -1914.45 & -1937.74 & 1.03 & 1.04 & 0.527 \\
\hline
\end{tabular}

In Table 6, the radial adjustment value refers to the proportionately increased quantity that is needed for all the output elements when technology efficiency is improved to 1 . The transverse adjustment value refers to the decreased quantity that is needed for all the input elements after the relative reference value is taken into consideration. The transverse adjustment ratio equals the absolute value of transverse adjustment divided by the original value.

In terms of the radial adjustment value, provinces with lower technology efficiency have a larger radial adjustment value, which means that higher proportionately increased quantity is needed for output elements. The transverse adjustment value must be proportionately decreased to keep the current output scale in each province. That is to say, the optimal production efficiency must be achieved with less input. Hainan performs better among these five provinces with its technology efficiency standing at 0.625 , while Yunnan has the worst performance among these five provinces with its technology efficiency standing at 0.302. The radial adjustment value of Hainan is 4750.95 and 
the radial adjustment ratio is $0.37 \%$ while the radial adjustment value of Yunnan province is 8839.85 and the radial adjustment ratio is $0.70 \%$. The data show that the optimal production efficiency can be reached in Hainan and Yunnan provinces only after the output elements in these two provinces respectively reach 4750.95 and 8839.85 .

In terms of transverse adjustment value in five provinces, it can be concluded that an irrational structure exists in Guangxi, Yunnan, Hainan, Fijian, and Jiangxi. If the current scale of output is kept unchanged, then the optimal production efficiency can be achieved only after some of the input elements are removed. Among the elements, the cost of labor is a stable factor when it comes to consider the effect placed on the production efficiency. Table 3 shows that the highest cost for labor, which needs to be decreased in Hainan province, is 4949.96 with its adjustment ratio at $2.65 \%$, and service cost needs to be decreased 1150.95 with its adjustment ratio at $0.62 \%$.

In terms of transverse adjustment ratio, the technology efficiency in Fujian province is closest to the reference value. It means that Fujian's OTE is the best one in the five provinces, and it is closest to the best technology efficiency value 1 . Fujian has the lowest value of transverse adjustment with its adjustment ratio of materials and services standing at $0.31 \%$ and $0.94 \%$, and only needs a decreased service cost and labor cost with 575.40 and 1750.87. Last but not least, in Guangxi, the biggest province for cassava production, CET only achieves 0.34 , has a large ratio of transverse adjustment on average, and service and labor cost stands at $1.71 \%$. This shows that $1.70 \%$ of the services cost and $1.72 \%$ of the cost for labor need to be eliminated to keep the current output scale in Guangxi province. Meanwhile, service and labor costs need to be reduced by 3164.85 and 3209.92 to achieve the best production efficiency.

\section{Conclusions and Implications on Policy}

\subsection{Cassava Cultivation Industrialization and Large-Scale Cultivation}

If the agriculture-production department, which mainly deals with input elements, wants to improve the production efficiency of cassava, they will achieve optimal production efficiency when the production scale and output improves. Therefore, enhanced field management, high-quality seeds, and improved cultivation methods are needed for a larger output of cassava and decreased cost of input. Cassava production on a large scale and industrialization will help a lot in maximizing the output when input stays unchanged.

\subsection{Increase the Yield by Further Improving Cultivation Technology}

OTE, PTE, and SE of five provinces are inefficient. Meanwhile, Guangxi, as a major cassava-producing province, still has room to improve its efficiency of input and output. In Yunnan province and Jiangxi province, the costs for labor are lower and the marginal land resources are larger. These advantages can be utilized and give these two provinces the best potential for large-scale cassava production. Another suggestion is that China should attach more emphasis on technology to improve the cassava industry, satisfy processing demand for raw materials by constructing a raw-material base, and incentivize farmers financially.

\subsection{Strengthen Cooperation with ASEAN and Africa}

African and ASEAN countries have superior natural resources for cassava planting, and a low-cost labor pool. In Africa, cassava is gradually becoming a cash crop for urban consumption, and being used as a livestock feed and industrial raw material [30]. In Thailand, farmers have a strong tradition of cassava cultivation. With limited land resources in China, it is difficult to expand the area of cassava cultivation. However, China can take advantage of the superior resources of Africa and ASEAN to strengthen cooperation with the major producers of cassava in Africa and ASEAN, encourage Chinese enterprises to invest abroad, develop the cassava industry, and subsequently feed the cassava processing industry in China. 


\subsection{Future Research}

There are some limitations that need to be studied further in future research. Quantitative analysis is sometimes insufficient. Due to the limits of the data, this research does not further the quantitative research of the price relationship among fresh tapioca starch, cassava modified starch, cassava alcohol and cassava fuel ethanol. Another future research direction is to analyze the impact the price of cassava has on the whole cassava industry. On the other hand, the research scope could be widened as well. In this paper, a microlevel study of the development of the Chinese cassava industry is used, but a macro view could also be used. Under the background of the Chinese "one belt one road" strategy, studying the mode of industrialization development and the effect of the Chinese "one belt one road" strategy on the cassava industry could be done in the future. Another limitation is the lack of up-to-date public data on cassava production, especially with respect to the cost. This is the reason why the data for this study are limited to 2014. However, it would have been more insightful if recent data were available.

Author Contributions: H.F. designed the research framework and is the main author; Y.Q. contributed sections of the paper and is the corresponding author; Y.P. contributed to the data processing and analysis.

Funding: This paper was funded by Hainan Provincial Natural Science Foundation of China (717078), and Tropical Crops Genetic Resource Institute, Chinese Academy of Tropical Agricultural Sciences (CATAS) (1630032014039).

Acknowledgments: The authors gratefully acknowledge the support of NSFC of Hainan, CATAS. Thanks also to the China Scholarship Council (CSC) for funding, the people who accepted the interview and provided necessary information and great thanks to Yu Xiong (Northumbria University) and Tao Wang (University of California, Riverside) for their intelligent discussions concerning the research. We thank Qing Ji (Hainan University) for sharing the data for this research. Finally we thank the anonymous reviewers for their helpful and constructive comments.

Conflicts of Interest: The authors declare no conflict of interest. The funders had no role in the design of the study; in the collection, analyses, or interpretation of data; in the writing of the manuscript; and in the decision to publish the results.

\section{References}

1. Burns, A.E.; Bradbury, J.H.; Cavagnaro, T.R.; Gleadow, R.M. Total cyanide content of cassava food products in Australia. J. Food Compos. Anal. 2012, 25, 79-82. [CrossRef]

2. Srinivas, T. Industrial demand for cassava starch in India. Sect. Soc. Sci. Cent. Tuber Crop Res. Inst. 2007, 59, 477-481. [CrossRef]

3. Cock, J.H. Cassava: A basic energy source in the tropics. Science 1982, 218, 755-762. [CrossRef] [PubMed]

4. $\mathrm{Hu}, \mathrm{Z}$; Fang, F.; Ben, D.; Pu, G.; Wang, C. Net energy, $\mathrm{CO}_{2}$ emission, and life-cycle cost assessment of cassava-based ethanol as an alternative automotive fuel in China. Appl. Energy 2004, 78, 247-256. [CrossRef]

5. Zhu, W.; Lestander, T.A.; Orberg, H.; Wei, M.; Hedman, B.; Ren, J.; Xie, G.; Xiong, S. Cassava stems: A new resource to increase food and fuel production. GCB Bioenergy 2015, 7, 72-83. [CrossRef]

6. Mombo, S.; Dumat, C.; Shahid, M.; Schreck, E. A socio-scientific analysis of the environmental and health benefits as well as potential risks of cassava production and consumption. Environ. Sci. Pollut. Res. 2017, 24, 5207-5221. [CrossRef] [PubMed]

7. Huang, J.; Li, K.; Ye, J.; Qin, H.; Shao, N.; Chen, M. A summary review of dominant regions of cassava growing in China. Guangxi Agric. Sci. 2008, 1, 104-108.

8. Jin, S.; Sun, S. Analysis of Raw Material Resources for Non-grain Fuel Ethanol in China. Sino-Glob. Energy 2011, 16, 40-45.

9. $\mathrm{Fu}, \mathrm{H} . ; \mathrm{Li}, \mathrm{K}$. Cassava raw material price change trend and cause analysis in China. Price Theory Pract. 2016, 5, 127-129.

10. Food and Agriculture Organization of the United Nations. Available online: http:/ /www.fao.org/faostat/ en/\#data/TP (accessed on 5 August 2018).

11. Chai, Q.; Shen, W. Chinese cassava industry price supply elasticity. J. Tsinghua Univ. 2009, 49, 897-900.

12. Cooper, W.W.; Seiford, L.M.; Zhu, J. Data envelopment analysis. In Handbook on Data Envelopment Analysis; Springer: Boston, MA, USA, 2004; pp. 1-39. 
13. Jiang, D.; Hao, M.; Fu, J.; Huang, Y.; Liu, K. Evaluating the bioenergy potential of cassava on marginal land using a biogeochemical process model in Guangxi, China. J. Appl. Remote Sens. 2015, 9, 097699. [CrossRef]

14. Jiang, D.; Chen, S.; Hao, M.; Fu, J.; Ding, F. Assessing the sustainable development of bioenergy from cassava within “Water-Energy-Food" Nexus framework in China. Sustainability 2018, 10. [CrossRef]

15. Kolawole, P.O.; Agbetoye, L.; Ogunlowo, S.A. Sustaining World Food Security with Improved Cassava Processing Technology: The Nigerial Experience. Sustainability 2010, 2, 3681-3694. [CrossRef]

16. Poku, A.; Birner, A.; Gupta, S. Making Contract Farming Arrangements Work in Africa's Bioeconomy: Evidence from Cassava Outgrower Schemes in Ghana. Sustainability 2018, 10. [CrossRef]

17. Oladeebo, J.O.; Oluwaranti, A.S. Profit efficiency among cassava producers: Empirical evidence from south western Nigeria. J. Agric. Econ. Dev. 2012, 1, 46-52.

18. Abdulai, A.; Huffman, W. Structural adjustment and economic efficiency of rice farmers in northern Ghana. Econ. Dev. Cult. Chang. 2000, 48, 503-520. [CrossRef]

19. Amao, J.O.; Awoyemi, T.T. Adoption of Improved Cassava Varieties and Its Welfare Effect on Producing Households in Osogbo Adp Zone of Osun State, Nigeria. Gene Conserve 2008, 29, 498-519.

20. Foster, J.; Greer, J.; Thorbecke, E. A class of decomposable poverty measures. Econom. J. Econom. Soc. 1984, 1, 761-766. [CrossRef]

21. Awoyinka, Y.A. Cassava Marketing: Option for Sustainable Agricultural Development in Nigeria. Ozean J. Appl. Sci. 2009, 2, 175-183.

22. Yang, K.; Huang, J. Development potential of cassava fuel ethanol: Base on the perspective of farmers. Chin. Rural Econ. 2009, 5, 14-25.

23. Awerije, B.O.; Rahman, S. Profitability and efficiency of cassava production at the farm-level in Delta State, Nigeria. Int. J. Agric. Manag. 2014, 3, 210-218.

24. Ji, Q.; Fu, G.; Min, Y. Empirical analysis on cassava production in China. Guangdong Agric. Sci. 2014, 191-196. [CrossRef]

25. Marinoni, O. Development of a proxy for technical efficiency for specialized grain farmers. Comput. Electron. Agric. 2013, 96, 209-216. [CrossRef]

26. Aigner, D.J.; Chu, S. On estimating the industry production function. Am. Econ. Rev. 1968, 58, 826-839.

27. Charnes, A.; Cooper, W.W.; Rhodes, E. Measuring the efficiency of decision making units. Eur. J. Oper. Res. 1978, 2, 429-444. [CrossRef]

28. Coelli, T.J.; Rao, D. Total Factor Productivity Growth in Agriculture: A Malmquist index analysis of 93 countries, 1980-2000. Agric. Econ. 2005, 32, 115-134. [CrossRef]

29. Coelli, T. A Guide to DEAP Version 2.1: A Data Envelopment Analysis (Computer) Program; Centre for Efficiency and Productivity Analysis, University of New England: Armidale, Australia, 1996.

30. Phillips, T.P.; Taylor, D.S.; Sanni, L.; Akoroda, M.O. A Cassava Industrial Revolution in Nigeria; FAO: Rome, Italy, 2004. 